\title{
Emancipatory Social Work Education and Community Empowerment
}

\author{
Vishanthie Sewpaul*, Thobeka Ntini, Zama Mkhize, Snegugu Zandamela \\ School of Applied Human Sciences (SAHS), University of KwaZulu Natal (UKZN), South Africa \\ *Corresponding Author: Sewpaul@ukzn.ac.za(Vishanthie Sewpaul), ntinithobeka@gmail.com(Thobeka Ntini)
}

\begin{abstract}
In this article we discuss the links between emancipatory social work education and community empowerment. Based on Freirian-Gramscian-Althusserian theoretical analyses and praxis, we argue that the development of critical consciousness has the potential to contribute to radical and empowering social action. In doing so, we draw on the voices of students who have had the benefit of emancipatory social work education, and on our experiences in working in communities. Emancipatory social work education, rooted in critical and radical theories, highlights the iterative relationship between the personal and political dimensions of life, thus rendering the micro-macro dichotomy a false one. It thus brings into sharp focus the complex inter-relationship between agency and structure. Emancipatory social work is directed at heightening awareness of external sources of oppression and/or privilege that hold the possibility of increasing self-esteem and courage to confront structural sources of marginalization, oppression and exclusion.
\end{abstract}

Keywords Emancipatory Practice, Fieldwork, Critical Consciousness, Whole School Approach

\section{Introduction and Background}

This article describes community-based intervention adopting a whole school approach at an extremely disadvantaged school in a township in Durban, South Africa. Our entry into the school was borne out of a lengthy ten-year period of community-based practice and participatory research with children and youth living on the streets of Durban. The lead author worked with the students in a range of activities and research projects (see Sewpaul, Osthus \& Mhone et al, 2012; Osthus \& Sewpaul, 2014; Sewpaul, Osthus \& Mhone, 2014) that culminated in the production of a video, drawing on the lived experiences of youth living on the streets. The idea for the video emerged from the expressed desire of the youth living on the streets to make a constructive contribution. Some of them felt that it might have been too late for them but they wanted to prevent other children from leaving home and moving to the streets. Since the production of the video in 2010, the main author worked with different groups of students in schools to educate children, through small group participatory processes, about the dangers of street life, to identity the sources of support and help in their communities, and, engage children, teachers and parents in social work intervention in an effort to prevent migration to the streets. The pedagogical aim is to enable students to transfer lessons from the classroom and small group supervisory sessions to the practice context. As the requisite of community-based intervention is to respond to local contexts, the nature of the work has evolved over time. Educators and students bring to the teaching, learning and practice contexts their embodied selves, thus making it necessary to reflect on and deconstruct dominant discourses and practices, and to understand the relationship between the personal and the professional, which is central to emancipatory social work.

\section{Emancipatory Social Work Education and Practice}

Social work must, first and foremost, be about emancipation. To emancipate means to free ourselves from the shackles of historical, masculine, cultural and political domination; to authentically connect with ourselves and with others; and to examine and re-examine our common sense, taken-for-granted assumptions about ourselves, and the world around us (Althusser, 1971; Dominelli, 2002; Freire, 1970, 1973; Gramsci, 1971, 1977; Giroux, 1983, 1997, Levinas, 1985). In doing so we free ourselves from the constraints of society, develop moral courage to confront and challenge social injustices and human rights violations, and we develop greater belief in ourselves. This is salient, as most South Africans constitute a subaltern post-colonial and post-apartheid group, emerging from a prolonged history of oppression, marginalization and exclusion. 
In view of colonial and apartheid legacies of skewed power relations and the silencing of subaltern voices, emancipatory social work is particularly mindful about societal reproductions of power and powerlessness. Yet this does not deny the heterogeneity of the colonized (Spivak, 1988; Gramsci, 1971). Post-colonial theorists consider how criteria like class, race, caste, gender, sexuality, culture, religion, nationalism, and colonialism intersect to produce subordination, and how subaltern groups are excluded socially, economically, politically and geographically. Pertinent to community development, is the way in which modernisation theory constructed societies, creating dominant ideologies about inferiority and superiority and what constitutes development, which are unquestioned, thereby reproducing professional imperialism (Midgley, 1981). Conradie (2011) avers that: "The questions "why," "by whom" and "for whom" were [...] only asked much later, after a set of North American and Eurocentric assumptions and values had already been internalised as global norms for development' (p. 313).

Emancipatory social work is directed at developing counter-consciousness to such hegemonic norms and practices. Community-based social work must be stripped from its colonial legacies and imbued with meanings consistent with an emancipatory approach that has - at its heart - people centred empowerment, consciousness raising, participation and ecological development (Sewpaul and Larsen, 2014). Emancipatory social work draws on Freire's (1970; 1973) popular education and Gramsci's (1971) thesis of the organic intellectual, foregrounding the important roles of educators and social workers as facilitators. Gramsci (1971) argued that on account of ideological hegemony, change could not come from the masses, at least not at the beginning, except through the mediation of intellectuals. Thus, Sewpaul and Larsen (2014) point to the important role of social workers as public intellectuals in community education. Although ideology is false consciousness, it is, according to Althusser (1971), about the only consciousness we have. As products of our world, 'those who are in ideology believe themselves by definition outside ideology'. Given its non-conscious nature, the 'accusation of being in ideology only applies to others never to oneself' (p. 175). We therefore rarely recognise our own collusion in reproducing prejudices and stereotypes. It is difficult to think outside the box, but what Althusser offers is a critical self-consciousness that might contribute to the development of alternative paradigms. Critical theorists speak to the power of emancipatory pedagogical strategies as catalysts in engendering human agency. Hall (1985), for example, argued that 'we remain open to be positioned and situated in different ways, at different moments throughout our existence' (p. 103).

The role of ideology becomes critical to the extent that it has the potential to reveal truths by suspending belief and deconstructing historically conditioned social forces or to reinforce the concealing function of common sense. It is thus vital that common sense be subject to critical reflection
(Gramsci, 1971) so that we are able to shift from being the 'subjected being' to a subject that is the 'author of and responsible for its actions' (Althusser, 1971, p. 182). Developing consciousness of being part of a particular hegemonic influence, which includes an historical consciousness, is the first step in the process towards further progressive self-consciousness (Gramsci, 1971). Writing within the strengths-based perspective, Pulla (2014) highlights the importance of suspension of belief, empowerment, dialogue, collaboration, balancing power, validation and externalisation of problems.

Empowerment through consciousness-raising contributes to liberation, heightened feelings of self-esteem, efficacy and control, and supports the view that people have the capacity to reflect and to act. Through a praxis that enables an understanding of how external structural conditions contribute to oppression (Freire 1970; 1973) and/or privilege (Giroux 1997; Pease 2010) people are able to accept or reject certain elements, reframe issues and articulate change. Thus development cannot occur through macro level intervention alone. A critical reflection on one's own thinking and on one's social and political realities and the capacity to develop action strategies consequent upon these reflections is central to development. Our efforts must be directed at helping people to be emancipated from the constraints of their own common sense assumptions and from the structural constraints on their lives.

\section{Preparing Students for Emancipatory Practice}

In preparing students for practice, it is critical that educators begin with the life experiences of students. As part of an introductory course in the first year of study, the main author introduces to students the theories that underscore emancipatory social work education and practice. As part of the course requirement students write their biographies and engage in various forms of praxis. By writing and reflecting on their biographies, students locate themselves historically and in relation to their contemporary socio-political, economic and cultural worlds. They engage in debate and dialogue, examine the influence of societal discourses and practices on their thinking, and they are encouraged to challenge dominant discourses on religion, culture, race, class, nationality, disability and sexual orientation. In addition to classroom discussions and written case-based assignments, the latter is achieved through an on-line discussion forum, where students, among themselves debate critical issues such as homosexuality; gender; religion; specific forms of cultural practices linked to patriarchy; South African politics; and intimate femicide. One student, reflecting on this module, wrote: 'It cut through to the first causes of social problems.' Students began unsolicited, spontaneous discussion threads on the 2014 online forum. Several students commented on how the course challenged their thinking, exemplified in the words of one student: 'It 
has helped me realise that I have been judgmental my whole life and self-centred. But now I have changed through this course in such a way that I don't look at things the same way as I did before. Now I look at things with an open mind and I seem to question everything I see - even things I always believed in', while another wrote, 'Studying social work is the best decision I ever made because it has changed the way I think.'

The pedagogical strategies have often stimulated social action efforts, like signing petitions about the Protection of Information Bill in South Africa (which if passed into legislation would have severely compromised democratic practices) and writing to the State President about it, drawing up and signing petitions against anti-homosexuality legislation in Uganda and Nigeria, petitioning in support of students right to education, lobbying government to prevent the exclusion of poor students, lobbying for greater inclusion of disabled students and in support of a Basic Income Grant for all South Africans. The education is directed at helping students see themselves as players on national and global levels. Shukla (2009, p. 137) has described how 'subjective processes of self-transformation are [...] integral to global citizenship' (p. 137), while Hooks (1989) argued that the value of the narrative lies in theorising experiences as part of a broader politics of engagement.

In working with students in the classroom and in small group supervisory sessions, an overt objective is understanding and deconstructing ideology. Given the non-conscious nature of ideology as discussed above, this is a huge challenge. It requires a great deal of self-reflexivity and educators have an obligation to develop and use strategies to facilitate this. One of the strategies used in small group supervision in achieving the objective of self-reflexivity is journaling. One student wrote in her journal entry:

Journaling helps me to take a step back and look at situations from different perspectives. It has thus helped me to look beyond the personal problem ... It has helped me to constantly be aware of power dynamics, both among my colleagues and myself and the people I/we work with. It has furthermore helped me to always align what I am doing with my intentions; to scrutinise what is happening and compare with critical theories or the goal of social justice.

Reflecting on a recent supervisory session, of a five-hour duration during which time we shared breakfast, our life histories and identified possible connections between our personal and field practice experiences, one student in her journal entry wrote: 'Let me start off with supervision first, good breakfast, shared tears and great ambitions and ideas. After being in supervision, I realised that I have come so far with my life, which some people may have deemed to be hopeless. It made me go back to the real reason why I chose social work and really want to work with and for people. It made me realise that I am actually capable of doing so much'. Another student, who also commented on feeling very validated wrote: 'The supervision enabled members to know each other better, and to realise that we are all wounded healers'. Pulla (2014) quotes Saleeby, who asserted that: 'Stories and narratives often contain within their plots and characterizations evidence of strengths, interests, hopes and visions' (p. 41).

Regular on-site supervision and working with the students in-situ, validates them as persons and reinforces the emancipatory messages, where the challenge is to lift social work from only a micro analysis, to adopt more structural, critical and strengths-based approaches to practice, and to develop what Giroux called (1983) civic courage. There is a marked difference between being taught how to do something and observing skills, values and theory in action. Unfortunately social work education is increasingly being influenced by neoliberalism and new managerialism. Issues regarding citizenship and democracy are addressed within the restrictive language of markets, profit, individualism, competition and choice, which create indifference to inequality, hunger, deprivation, exploitation and suffering (Sewpaul, 2014). Educators and students must have moral courage and power of criticism, and must not, in the guise of objectivity, distance themselves from power relations that exclude, oppress, exploit and diminish other human beings. It is critical that educators model these qualities in confident, constructive and professional ways for the complex art of constructive confrontation to be learnt by emulation. In doing so various competing interests and ethical issues need to be considered in relation to service beneficiaries, organisational mandates and objectives, the needs of different categories of staff, funder requisites and expectations, the community, and available alternatives should the confrontation threaten to jeopardise services and/or the practice placement.

The aim towards 'great ambitions and ideas' are manifest in the students' field practices, as we work in non-pathologising ways with people (Pulla, 2014), heighten awareness of, and draw on the strengths of those that we engage with, and affirm our and social work's value as we engage relevant stakeholders and the media in highlighting local concerns and proposing solutions. In demonstrating the application of emancipatory social work we describe a project that we are engaged in. In 2013, the main author worked at a local Zee high school (For the purposes of anonymity, Zee is a pseudonym used for the school) located in the urban Inanda-Ntuzuma-KwaMashu (INK) area, in the province of KwaZulu Natal, with a group of students as part of their field practice education. Our primary mission was to undertake education in an effort to prevent migration of children to the streets of Durban. However, we engaged in a range of educational and therapeutic initiatives as teachers expressed concerns about sexual abuse, rape and poor academic performance. Before proceeding to detail the 
implementation of the current project, a brief profile of INK is provided.

\section{Brief Profile of the INK Area}

According to the DPLG (2014) the INK area shares the following socio-economic characteristics:

- The urban based population is about 580000 (2006 estimate) in an area that covers 70,1 square $\mathrm{km}$. The population density is 6325 persons per square $\mathrm{km}$.

- Over $65 \%$ of the population is younger than 29 years of age, the majority of whom are unemployed.

- $26 \%$ of the population is without electricity, $30 \%$ without piped water, $2 \%$ without waste removal services, and $67 \%$ are without fixed line telephones.

- $40 \%$ of the population is unemployed, with a further third (33\%) recorded as being economically inactive

- The high rate of poverty is directly related to the low rate of employment.

- Up to the 24-year-old INK population, 34\% have never attended school. Of those that attended school, only $22 \%$ had a Grade 12 level education. Only $4 \%$ attained a tertiary qualification.

- HIV prevalence is recorded at $39 \%$. South Africa has one of the highest rates of HIV infection in the world, with KwaZulu Natal being the epicenter of the virus; INK is one of the most infected areas within the province.

- In comparison with the real GDP growth in KwaZulu Natal, which was 3,7\% (2000-2004), INK's growth was only $1,3 \%$, characterized by jobless growth.

The largest percentage of people employed fall into the low paying occupational category (33\%), including domestic workers, street traders, office cleaners, security guards and waiters. A further $28 \%$ of those employed work within service industries (14\%) as shop assistants or sales personnel, and within crafting and related trades $(14 \%)$. The area is characterized by high rates of alcohol, drug abuse and crime, with Inanda regarded as the murder capital of KwaZulu Natal, followed closely by KwaMashu.

\section{The Reimagine Zee Project}

It is against the above profile that before re-entering the school in July 2014, we (a new group of students, who are co-authors to this chapter and the main author, their field supervisor) discussed the nature of the problems at the school and its environmental context that provide fertile ground for demoralization, helplessness and hopelessness. We discussed how we could possibly adopt a whole school approach including learners, teachers, parents and local business in a Re-imagine Zee school project. The resources and infrastructure of the school do not provide for a conducive learning environment. There is no playground, no tennis court or netball field; only dusty spaces between the school's blocks, no laboratory facilities and no school library. The conditions of classrooms are poor with crumbling ceilings, broken windows and walls sorely in need of painting. On positive notes the school is supported with a good school-feeding scheme by the Provincial Department of Education; there is a space for open assembly gathering; the learners are neatly dressed in uniform; the school is well kept and there is no littering; and the school choir had excelled having won several awards. We noted that the general levels of discipline among the learners were good, and that teachers were in classes teaching.

The Reimagine Zee project is based on the principles and strategies of the work of Imagine Chicago described by Browne and Adelman (2014). While the Imagine movement is based on working with cities, we chose to use the model in a smaller context of the school as community in view of time, human resource and financial constraints. Aligned with emancipatory practice and the strengths-based approach (Saleeby, 2013; Francis, Pulla, Clark, et al, 2014) Imagine Chicago emphasizes the following principles: 1) Hope is generative and provides the context for action; 2) Developing an animated, shared vision where everyone is valued and participates to counter 'the problem - and deficit-oriented public discourse' (Browne and Adelman, 2014 , p. 122) that demoralizes and counteracts hope and constructive change; 3) Framing positive questions with a focus on affirming experiences; and 4) Developing a sense of shared identity as citizens and a systems way of thinking.

The entry into the school in July 2014 was preceded by telephone calls to the Life Orientation (LO) teacher, Ms N who, on the basis of the positive experience of working with us in 2013, was happy to continue the relationship with the University. On visiting the school, before the commencement of their field practice, to introduce the students and the idea of the Reimagine Zee project, it became obvious that Ms $\mathrm{N}$ was feeling quite overwhelmed by immediate problems such as poverty, girls being absent or dropping out of school on account of not having sanitary pads; sexual abuse and rape; teen parents; and learners presenting with behavioural and learning difficulties. We tried to shift from a problem-oriented, pathology focus to giving vision to a whole school approach, wherein we deal with the range of issues within a more positive framework, including the possibility of paying attention to some of the school's infrastructure. But the intensity and range of problems were such that it was difficult to begin comprehending a cohesive community, coalescing around a positive vision with something like: "Zee: Our Hope, Our Future, Our Inspiration".

Within a week of the commencement of the field placement one of the students (Thobeka) wrote: 'There are pressing issues that we are encountering which are a threat to the desired progress especially with the sensitive individual cases.' Thobeka clarified that the 'desired progress' referred to the Reimagine Zee vision. As is characteristic of social 
work in South Africa, the problem is that there are far too many individual cases that need urgent attention. In a joint meeting we discussed the option of undertaking preliminary assessments and providing immediate support with appropriate referrals for individual case follow-up so that our time and energies could be focused on the broader developmental aspects of the work, aligned with a Reimagine Zee vision, which Ms N and the School Principal began to see the merits of. The major concern expressed by the Principal and teacher was threats of suicide received from learners. Two learners had committed suicide in the first semester, and the teachers were, rightfully, concerned about its possible ripple effects.

Teen suicide is a major social and public health concern on a global level (Pulla, 2014). A recent article by Malan (2014) indicates that one in four teens have attempted suicide and 1 in 3 hospital admissions for suicide in South Africa involve youth. South Africa has the eight highest suicide rate in the world. With $9.5 \%$ of teen deaths due to suicide, it is a problem of enormous concern. We intervened with individual learners, but we appreciated that suicide is not an individual affair and needs to be seen as a shared school and community problem. In keeping with our Reimagine Zee vision of a whole school approach, therapeutic individual (which we tried to keep to a minimum for long term cases by developing a system of referrals) and group work programmes dealing with identified concerns, were integrated with a large scale 'Suicide is not an option' campaign, drawing on the school's strengths and resources. The learners were aware of the suicides of their peers. Class discussions were held with the learners, and a small group of volunteers met over a brief period, but on an intensive and regular basis to plan a campaign for the whole school. The main aims were to break the silence and taboo around suicide, demystify it, get learners to talk about it in ways that make sense to them, know that help is available, and convey the message that suicide is not an option.

Drawing on the ideas and creative potential of the learners proved to be most productive and rewarding. While the students produced an excellently designed professionally printed poster, with salient anti-suicide messages, the learners crafted a hand-designed poster depicting a desolate young woman and a male youth death through suicide. The Principal and teachers cooperated to hold a special open assembly for the programme. During the open assembly with over 1300 learners one of the learners gave a powerful anti-suicide talk, aligned with the aims of the campaign. Another learner wrote and recited an anti-suicide rap poem, sending out profound messages through a medium that all learners found appealing. The learners that produced the poster, linked suicide to Shakespeare's Romeo and Juliet where suicide is romanticised, reminding us that youth can relate to each more effectively than we can with them as adults. They indicated that sometimes, young people think of suicide when they experience love problems, their appeal was to re-romanticise suicide. A group of learners got together to produce a song titled: 'It is not the only way.' Sewpaul, Osthus and Mhone (2014) highlighted how constructions of us as experts can betray our egalitarian ideals, and the importance of awareness of our relative privilege and power as social work educators, students and practitioners. We thus made conscious choices about ensuring the learners' participation in decision-making.

Although we initiated the idea of the campaign, the programme was incredible as suicide is generally not talked about and when people do, it is usually in hushed tones. Given the urgency of the matter the learners had, within a period of two weeks, put together an exceptionally creative and appealing programme. Following the assembly, dialogue sessions were held in classes and in small groups as a means of debriefing and processing the information communicated at the assembly. As the main message was consistently reinforced during the assembly, even teachers were heard after that repeating: 'Suicide is not an option.' As a follow up to this, a community radio talk show took place on 28 September 2014, with participation by the students, a learner and the Principal.

This was followed up with an open meeting with parents where we, together with some of the learners, addressed parents on the prevalence of youth suicide, early warning signs, what can be done about it and community resources that are available. The plan was to arrive at mutually agreed upon decisions about sustained prevention efforts. As the anti-suicide campaign is one part of a larger Reimagine Zee Project, the goal is to establish a Committee with learner, parent and teacher representation to further the activities of the Project. These include broadening and fostering the collaboration with the local service organizations for those learners in immediate material need and other psychosocial assistance; coordination of the functions of the Fundraising and Welfare Committees within the school; networking with local business to raise funds to ensure that the girls have sanitary pads, and to paint and renovate at least one or two classrooms.

\section{Community Empowerment Goals and Principles of the Reimagine Zee Project}

There are several goals achieved via the Reimagine Zee project:

- Building and strengthening relationships among learners, teachers, parents, community service organizations and local business to realize the vision of Reimaging Zee.

- Adopting an inclusive approach in beginning a process of building the physical infrastructure of the school, which will engender a sense of pride, hope and ownership. An uplifting physical environment can contribute to enhanced teaching and learning, and to the validation of teachers and learners. Thus, 
renovating one or two classes becomes symbolic of pride, an affirmation of human dignity, and a tangible expression that change is possible in the spirit of 'together we can.'

- Building on the existing strengths and structures within the school and enhancing coordination of services with the Fundraising and Welfare Committees in the school, and the joint committee of learners, teachers and parents.

- Building on learners' talents, confidence and problem-solving skills, as we serve as facilitators and work with them in realizing the school's mission of promoting the holistic development of learners.

- Skills development, capacity building and nurturing leadership potential. Learners were at the forefront of the suicide is not an option campaign and they suggested programme design and content. The students, as facilitators, also developed their own capacities and leadership skills. The programme built the confidence and public speaking skills of the learners and the students. In the words of the learners: 'As a group we discovered our talent of writing a song relating it to the anti-suicide campaign. We experienced difficulty in arranging the song and putting the words together however we managed to finally put the song together and achieved the goal that seemed almost impossible.' They also wrote that the campaign helped them to manage 'our fear of public speaking.'

- Modeled on creative leadership and visionary thinking, the students, learners and the Principal planned and participated in the community radio talk show, of an hour's duration, which was very validating for them, their families and the school. It is reflective of civic responsibility and engaged citizenship, which are at the heart of emancipatory education and practice.

- The empowerment based approaches adopted in engaging students and learners in small group tasks and in broader community initiatives, help heighten awareness of societal issues, e.g. the factors contributing to sexual abuse, rape, poverty and suicide, to realize that these are not of their own making, and that is not their fault. It is hoped that by externalization of problems and by increasing their hope, self-esteem and creative potential they would be able to confront and challenge structural sources of injustices. Learners and students are beginning to show potential for this e.g. challenging service organizations in the community about non-delivery and holding them accountable; noting the use of corporal punishment, which is illegal, amongst some teachers and discussing ways in which this can be best addressed.
In working on the Reimagine Zee project the following principles were evident:

- Beginning where people are. We listened and responded to the expressed concerns of the teachers and learners as we dealt with learners' psychosocial problems through casework, networks of referrals; educational and therapeutic group work. In doing so we did not abandon our Reimagine Zee vision of a whole school approach as we engaged in the suicide is not an option campaign, and in beginning with building the infrastructure of the school. We engaged the learners, the Principal and the teachers to earn their buy-in into the Reimagine Zee project, to look beyond the immediate problems of individual learners, which tend to be a more normalized and conventional approach. While affirming the centrality of beginning where people are, Sewpaul and Larsen (2014) assert that 'But, as the goals are development and change, people must make shifts in their thinking, values, attitudes and behavior and/or structural conditions (p. 239).

- Respecting local values and language. The learners developed a programme consistent with the values of the youth through a genre that appealed to them, and they communicated in the English and local isizulu languages. The community radio talk show was conducted in isiZulu to meet the needs of the local community, and to respond to local realities.

- The use of collaborative, not top down leadership; modeling this with students facilitates them emulating this in practice.

- Validation of people by tuning into their life worlds, and building on their strengths and capacities. Validation is one of the most important empowerment strategies available to educators and human service professionals.

- Setting a clear vision and aligning goals and strategies with the vision, while allowing for flexibility as community development often means dealing with unanticipated events and issues.

- Inspiring people's passions and imaginations to realize their strengths, and to envision and influence change and development.

- Stimulating the most marginalized and silenced groups into participation. This is based on the realization that 'while it take power to participate, participation engenders power' and that indeed 'participation is power' (Sewpaul and Larsen, 2014, p. 240). Participation does bring intrinsic rewards, builds confidence and self-esteem, gives people some measure of control over life issues and instills hope for the future, all of which are key to emancipatory, empowerment based practice. 


\section{Conclusion: Challenges and Future Directions}

Given the socio-economic deprivation of the INK area, the school serves as a microcosm of the social problems that dominate marginalized communities. Our entry and experience at Zee has been over a brief period, and we engage with the school in the second semester. One of the main reasons for this, are shifts in higher education, with greater neoliberal influences and commodification (Sewpaul, 2014) that sees a drive for higher enrolment targets without the requisite staffing to go with it. This has meant large intake of students into the BSW programme. While in the past, when we had more reasonable student numbers, field practice education occurred on a year-long basis, this has been restructured into a three and half month internship. This means that schools such as Zee, which are desperately in need, are without the service for the greater part of the year. As there are no school social work services, this leaves huge gaps in services and raises ethical concerns about fulfilling higher education imperatives, rather than responding to the needs of the community. One of the greatest challenges is ensuring that a credible, productive and sustainable service is provided as different groups of students benefit from service learning. While we engage in the politics of resistance and attempt to alter the neoliberal influences at the level of the institution, we have to devise pragmatic ways of trying to ensure continuity of the work at the school. One way is the establishment of the joint parent, teacher and learner committee that hopefully will continue activities in the Reimagine Zee Project, with intermittent contact with the university, until the next group of students are placed there to pick up and elaborate on the work in more decided ways.

While our engagement at the school has made some tangible differences, we appreciate that in the face of deprivation and marginalisation, our efforts produce only small gains. Politicians and education authorities need to commit to working in the best interests of our children and in providing the best possible holistic education for them. Employing social workers in schools can go a long way in attending to the psychosocial needs of children and in adopting a whole school approach, wherein teachers, children and their families can take pride in schools and what they have to offer. We have sown the seeds and demonstrated that Zee is pregnant with possibilities for constructive engagement, change and development. Hopefully, our intervention has left the teachers, parents and learners with the message that they are not passive victims of society's control elements, that they have agency and the confidence to challenge, confront and deal with structural injustices and oppressions, and that in time they would be able to truly link in with the Reimagine vision of 'Zee - Our Hope, Our Future, Our Inspiration.

\section{REFERENCES}

Althusser, L. (1971). Ideology and ideological state apparatuses (translated by B. Brewster) in L. Althusser (Ed.). Lenin and philosophy, and other essays, London: New Left Books.

Browne, B. \& Adelman, C. B. (2014). How to make room for all? The power of context in shaping action, In A. K. Larsen, V. Sewpaul, \& G. Oline (Eds.), Participation in community work: International perspectives. London: Routledge.

Department of Provincial and Local Government (DPLG) (2014). Inanda, Ntuzuma, KwaMashu (INK) Nodal Economic Development Profile

http://www.durban.gov.za/Documents/City Government/IDP Poli cy/01\%20INK narrative.PDF. Accessed 24 September 2014

Conradie, I. (2011). Human development and development intervention: Can community development increase capabilities? The Social Work Practioner-Researcher, 23 (3): 310-326.

Dominelli, L. (2002). Anti-oppressive social work theory and practice. Basingtoke: Palgrave Macmillan.

Francis, A. P.; Pulla, V.; Clark, M.; Mariscal, E. S.; \& Ponnuswami, I. (2014). (Eds.), Advancing social work in mental health through strengths-based practice. Brisbane, Primrose Hall Publishing Group.

Freire, P. (1970). The pedagogy of the oppressed. Harmondsworth, England: Penguin Books.

Freire, P. (1973). Education for critical consciousness. New York, NY: Seabury Press.

Giroux, H. A. (1983). Theory and resistance in education: A pedagogy for the opposition. London, England: Heinemann.

Giroux, H. A. (1997). Pedagogy and the politics of hope: Theory, culture and schooling. Boulder, CO: Westview Press.

Gramsci, A. (1971). Selections from the prison notebooks. In A. Hoare \& G. N. Smith (Eds. \& Trans.). London, England: Lawrence \& Wishart.

Gramsci, A. (1977). Selections from political writings 1910-1920. London, England: Lawrence \& Wishart.

Hall, S. (1985). Signification, representation, ideology: Althusser and the post-structuralists debates. Critical Studies in Mass Communication, 2, 91-114.

Hooks, B. (1989). Talking back. Boston, MA: South End Press.

Levinas, E. (1985) Ethics and infinity. Translated by R. A. Cohen. Pittsburgh: Duquesne University Press.

Midgley, J. (1981). Professional imperialism. Social work in the third world, London, Heineman.

Osthus, I. S. \& Sewpaul, V (2014). Gender, power and sexuality among youth on the streets of Durban. International Social Work, 57(4): $325-336$

Pease, B. (2010). Undoing privilege: Unearned advantage in a divided world, London: Zed Books. 
Pulla, V. (2014). Strengths-based perspectives in mental health, In A. P. Francis,; V. Pulla,; M. Clark, et al. (Eds.), Advancing social work in mental health through strengths-based practice. Brisbane, Primrose Hall Publishing Group.

Saleebey, D. (Ed.). (2013). The strengths perspective in social work practice Boston: Pearson.

Sewpaul, V. (2014). Social work education: Current trends and future directions. In C. Noble, H. Strauss \& B. Littlechild (Eds.). Global social work: Crossing borders, blurring boundaries. Sydney: Sydney University Press.

Sewpaul (2013). Inscribed in Our Blood: Confronting and Challenging the Ideology of Sexism and Racism, Affilia, The Journal of Women and Social Work 28 (2): 116-125.

Sewpaul, V. \& Larsen, A.K. (2014). Community development: Towards an integrated emancipatory framework, In A. K. Larsen, V. Sewpaul, \& G. Oline (Eds.), Participation in Community Work:
International Perspectives. London: Routledge.

Sewpaul, V.; Osthus, S.; Mhone, C.; Sibilo, E. \& Mbhele, S. (2012). Life on the streets of Durban: No millionaire ending. Social Work/Maatskaplike Werk, 48 (3): 241-254.

Sewpaul, V.; Osthus, I. \& Mhone, C. (2014). Power and participation in community work research and practice. In A. K. Larsen; V. Sewpaul \& G. Oline (Eds.), Participation in Community Work: International Perspectives. London: Routledge.

Shukla. N. (2009). Power, discourse, and learning global citizenship: A case study of international NGOs and a grassroots movement in the Narmada Valley, India. Education, Citizenship and Social Justice. 4 (2): 133-147.

Spivak, G. C. (1988). Can the Subaltern speak? In C. Nelson \& L. Grossberg (Eds.), Marxism and the interpretation of culture. Chicago: University of Illinois Press. 